\title{
Steroid Phobia: Is There a Basis? A Review of Topical Steroid Safety, Addiction and Withdrawal
}

\author{
Sean Yilong $\operatorname{Tan}^{1} \cdot$ Nisha Suyien Chandran ${ }^{1,2} \cdot$ Ellie Ci-En Choi ${ }^{1}[$
}

Accepted: 27 July 2021 / Published online: 18 August 2021

(c) The Author(s) 2021

\begin{abstract}
There is a growing concern amongst patients about topical corticosteroid (TCS) side effects, with increasing discussion of topical steroid addiction (TSA) and topical steroid withdrawal (TSW) particularly on social media platforms. However, the acceptance of TSA/TSW as a distinct condition remains controversial within the dermatological community. We conducted a literature search using PubMed, MEDLINE, Cochrane Library, Google Scholar, Embase and Web of Science to identify original articles addressing TSA/TSW. We described the definition and reported clinical features of TSA/TSW including its classification into erythemato-edematous and papulopustular subtype. To assess the validity of TSA/TSW, we summarised and objectively appraised the postulated mechanisms for this condition, including tachyphylaxis, dysregulation of glucocorticoid receptors, rebound vasodilation and impaired skin barrier leading to a cytokine cascade. Understanding the evidence including its limitations and uncertainties highlights areas for future research and helps medical practitioners better counsel and provide care to patients who may be experiencing or who have concerns about TSA/TSW.
\end{abstract}

\section{Key Points}

Topical steroid addiction and withdrawal encompasses the concept of dependence on topical steroids with worsening skin signs after its cessation. Skin manifestations may be more extensive or of a different morphology from the primary dermatosis.

Tachyphylaxis, dysregulation of glucocorticoid receptors, rebound vasodilation and impaired skin barrier leading to a cytokine cascade are plausible pathomechanisms, although evidence is insufficient.

Nisha Suyien Chandran

nisha_suyien_chandran@nuhs.edu.sg

1 Division of Dermatology, Department of Medicine, National University Hospital, 5 Lower Kent Ridge Road, Singapore 119074, Singapore

2 Department of Medicine, Yong Loo Lin School of Medicine, National University Singapore, 10 Medical Dr, Singapore 117597, Singapore

\section{Introduction}

Topical corticosteroids (TCS) have a range of known side effects including skin atrophy, telangiectasia, tinea incognito and steroid rosacea (Table 1) [1, 2]. However, concepts such as topical steroid addiction (TSA) and topical steroid withdrawal (TSW) are controversial with majority of the dermatological community questioning this entity. Differences in opinion between dermatologists and patients who believe in TSA/TSW create challenges in treatment and a failure to acknowledge the patient's concerns can result in a weakening of the patient-healthcare relationship (ongoing study).

Concerns about TSA/TSW contribute to TCS phobia, which has a prevalence ranging from 21 to $83.7 \%$ [3]. Studies using the TOPICOP score ${ }^{\odot}$ [4], a validated score to assess steroid phobia, have found an average score of between 40.3 and 44\% (0 least fear, 100 most fear) [5-7]. Importantly, excessive TCS concerns can lead to excessive food restriction [8], use of harmful alternatives [9], and suboptimal treatment [3], resulting in flares and escalation to systemic agents.

In 2015, the National Eczema Association (NEA) task force presented a systematic review including 1085 patients reported to have TSW [10]. Authors concluded that TSW is a distinct clinical event, but acknowledged that studies included were of "very low" quality. The review was updated 
Table 1 Local side effects of topical corticosteroid (TCS) and their proposed mechanisms

\begin{tabular}{ll}
\hline Local side effect & Proposed mechanism \\
\hline Atrophy & $\begin{array}{c}\text { Reduction in epidermal and dermal thickness through suppressive action on keratinocyte and fibroblast } \\
\text { proliferation [32, 34, 44] and inhibition of collagen and lipid synthesis [64, 80] } \\
\text { Velangiectasia } \\
\text { Purpura }\end{array}$ \\
$\begin{array}{l}\text { Dermal atrophy and loss of intercellular substance causing blood vessels to lose the support of dermal } \\
\text { matrix [82, 83] }\end{array}$ \\
Striae & $\begin{array}{c}\text { Abnormal cross linking of collagen, reduction in dermal and connective tissue support [84, 85] that } \\
\text { increases susceptibility to mechanical stretch [85, 86] }\end{array}$ \\
Hypopigmentation & Reduction in number and activity of melanocytes [87] \\
$\begin{array}{l}\text { Delayed wound healing } \\
\text { Hypertrichosis }\end{array}$ & TCS affects keratinocytes, fibroblasts, vascular connective tissue and angiogenesis [88] \\
Acneiform eruption, including & Stimulation of vellus hair growth by unknown mechanism [89] \\
steroid rosacea and perioral & Not well understood. Proposed mechanisms include altered microbiome (e.g. an increase in demodex mites \\
dermatitis & [90]) and degradation of follicular epithelium [91] \\
Cutaneous infections & Steroids mask the local immune response and falsely alludes to a clinical response while the infective \\
& organisms propagates (e.g. tinea incognito, Malassezia folliculitis) [92, 93] \\
\hline
\end{tabular}

in 2020 by Hwang and Lio and obtained consistent findings [11]. This present review aims to incorporate and evaluate what is known not just clinically, but also pathophysiologically about TSA/TSW through a comprehensive scoping of the literature. We searched PubMed, MEDLINE, Cochrane Library, Google Scholar, Embase and Web of Science to identify articles addressing TSA/TSW published from database inception to 16 th June 2021. The following search terms were use "topical steroid", "topical corticosteroid", and "addiction", "withdrawal", "dependence", "tachyphylaxis" and "rebound". Hand searching of references of relevant articles was also performed. Information on definition, risk factors, clinical presentation, proposed pathogenesis, treatment and prognosis were extracted and summarised herein.

\section{Definitions}

The terms TSA and TSW appear to be used interchangeably without a clear diagnostic criteria or definition. Clinically, TSA/TSW has been described as a physical dependence on corticosteroids, with worsening of skin manifestations after withdrawal of TCS [10-14]. This rebound may be more extensive or with a different morphological appearance from the initial skin condition [15]. Some describe a decreasing effectiveness and an increase in quantity and potency of TCS required to control the skin condition $[12,16]$. Psychological dependence may coexist, with resistance to stop despite awareness of its harmful consequences [13].

Other related terms include topical steroid damaged/ dependent face (TSDF), red skin syndromes and red burning skin syndrome [12, 17-19]. TSDF was defined as the 'semi-permanent or permanent damage to the skin of the face precipitated by the irrational, indiscriminate, unsupervised, or prolonged use of TCS', reported in the context of over-the-counter TCS containing lightening creams [18, 19]. Rapaport and Rapaport reported the "red skin syndromes", described as a distinct patterns of chronic worsening eczematous rash including red face syndrome, post-peel syndrome, status cosmeticus, red scrotum syndrome, vulvodynia, perianal atrophoderma, chronic actinic dermatitis and chronic severe eczema $[12,17,20]$.

While some authors include perioral dermatitis and steroid rosacea in their definitions of TSA/TSW [10, 14, 21] others consider these as being distinct [22].

\section{Risk Factors for TSA/TSW}

Studies that look at TSA/TSW in the context of predominantly inflammatory skin conditions indicate an that an equal number of males and females are at risk [16, 23], while those with mainly cosmetic use report a female majority $[10,11$, 19].

The increased permeability of the stratum corneum is postulated as a risk factor [14, 24], with the face, and genital area having the highest percutaneous penetration [25] and thus being the most commonly affected sites [10, 11, 16]. The context for TCS use includes atopic dermatitis (AD) [10-12, 16, 26-28], cosmetic use and pigmentary disorders [10-12, 18, 19, 21], scrotal erythema [12], acne [10-12, 19, 28], rosacea [10, 28, 29] and perioral dermatitis [10]. Duration of TCS use ranged widely from 2 months to 40 years $[11,16,21,23]$, being typically of mid- to high-potency [10, $11,16]$. Longer periods of application and increased potency are believed to be risk factors for TSA/TSW [17, 28], with 
a longer period of TCS use associated with greater rebound symptoms $[7,28]$.

\section{Clinical Presentation of Patients Reported to have TSA/TSW}

Clinical findings reported include oedema, vesiculation, prominent erythema, burning disproportionate to itch and erythema, and features of chronic steroid use such as telangiectasia, skin atrophy and acneiform papules resembling rosacea $[11,12,16,17,26,28,30]$. While such features are not specific, patients and authors have described these to be symptomatically and morphologically different from their primary dermatoses. Additionally, symptoms may be more severe with a questionnaire study reporting that $63.9 \%(529 / 828)$ of respondents had their most severe AD symptoms immediately after discontinuation of TCS [7]. Specific signs such as "red sleeve sign" and "elephant wrinkles" have also been described (Table 2). Following a systematic review, Hajar et al observed and reported 2 subtypes of patients with TSA/TSW; an erythemato-edematous subtype that occurred in patients with an underlying eczematous dermatosis, and a papulopustular subtype that occurred in patients who used TCS for a cosmetic or acneiform condition [10].

These are the phases of TCS withdrawal proposed based on previous observations [15, 31].

I. An acute red exudative phase that starts typically a few days after cessation of TCS. This rebound erup- tion extends to areas of the skin where TCS have never been applied $[14,15,17]$.

II. A dry itchy desquamative phase ensues.

III. A recovery phase where the skin shows gradual improvement but is "sensitive" to minute stimuli. Periods of aggravation and flares may occur intermittently [17]. Sensitivity decreases over time.

IV. A recovered phase where the skin returns to its original appearance, which may be completely healthy or that of the original skin condition (e.g., in AD). The entire process of recovery may take weeks to years [15].

\section{Differentials}

Prior to the diagnosis of TSA/TSW, patients were often given alternate diagnosis including worsening of the underlying dermatitis, allergic contact dermatitis, rosacea and systemic lupus erythematosus (due to facial redness) [12].

\section{Pathogenesis}

Topical corticosteroids work at the cellular level via genomic and non-genomic pathways to achieve anti-inflammatory, antiproliferative, immunosuppressive and vasoconstrictive effects [32-35]. The genomic pathway refers to the actions of the glucocorticoid receptor and its subsequent transcriptions of genes with anti-inflammatory functions and downregulation of pro-inflammatory genes. The non-genomic pathway is responsible for the rapid effect of TCS by affecting target

Table 2 Reported signs and symptoms of TSA/TSW

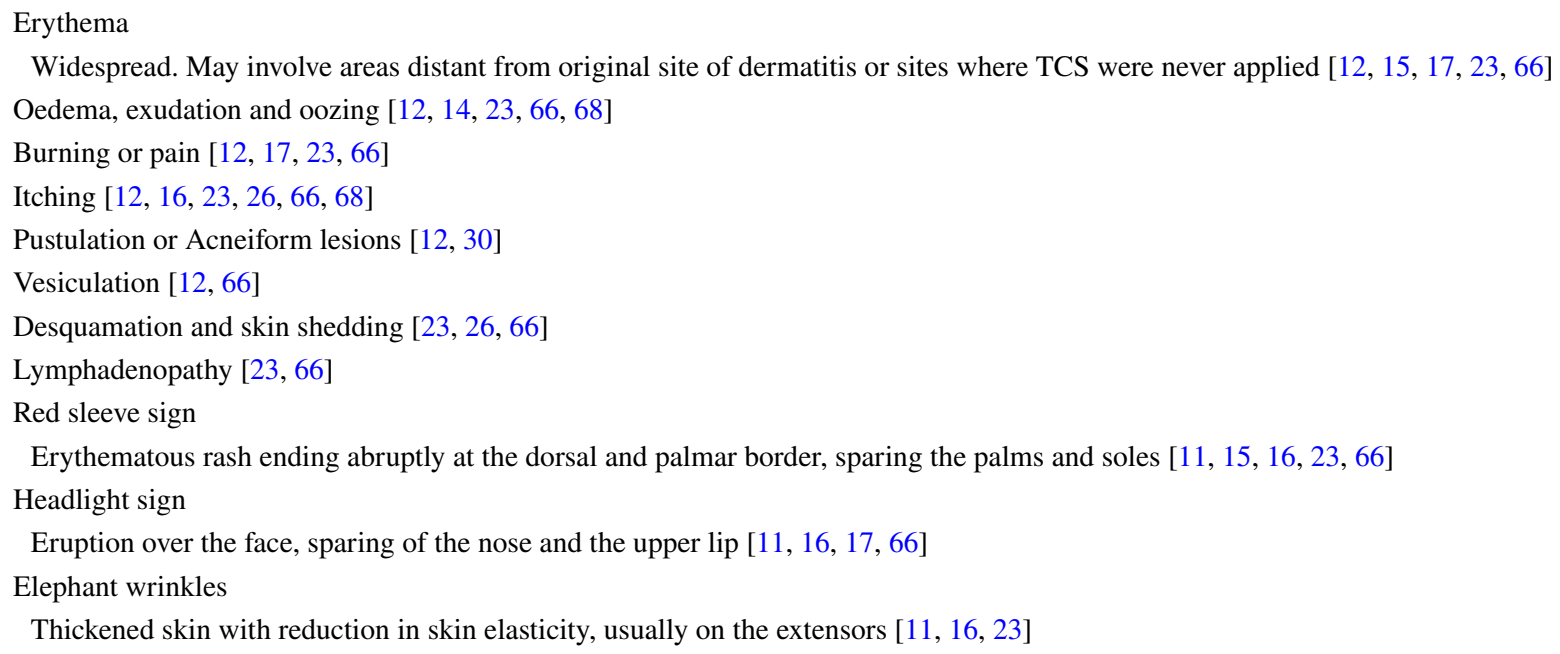

These findings are reported from clinical observations, and objective differentiation from the primary dermatoses is challenging TCS topical corticosteroid, TSA topical steroid addiction, TSW topical steroid withdrawal 
cells such as monocytes, $\mathrm{T}$ cells and platelets without the use of protein synthesis.

Particular mention should be made of steroid-induced atrophy as this is a common concern. Steroid-induced atrophy results from inhibition of cell proliferation and collagen synthesis (Table 1) [36, 37]. This is dependent on the duration of use [38], potency [39], and anatomical area treated $[2,40]$. Although the degree of steroid-induced atrophy is proportionate to the above factors, previous studies suggest that skin thickness returns to normal values in approximately 2 weeks following discontinuation of TCS treatment. However, these studies were conducted in patients with normal skin and short periods of TCS use, which may not translate to real-world conditions in patients with chronic inflammatory skin disorders [38, 41, 42].

\section{Postulated Mechanisms for TSA/TSW}

\subsection{Tachyphylaxis}

Tachyphylaxis, the decreasing effect of TCS when applied continuously, has been shown in small studies [43-46]. In 1976, du Vivier et al. showed that the initial three to five applications of TCS to mouse skin resulted in inhibition of DNA synthesis, but DNA synthesis increased after 7 applications before returning to normal with 13 applications [44]. Both twice-daily and alternate-day application of TCS resulted in this same pattern but was less marked in the alternate-day group [43]. A decrease in vasoconstrictive response [45] and histamine-induced wheal suppression [46] have also been reported with repeated TCS applications. These suggest that continued TCS application may result in insensitivity to its anti-proliferative, vasoconstrictive and histamine suppressive effects.

Interestingly, TSA/TSW is rarely reported in psoriasis patients and further research and comparison between psoriasis and atopic dermatitis may shed greater understanding of the pathogenesis of TSA/TSW.

\subsection{Dysregulation of Glucocorticoid Receptor}

The therapeutic action of glucocorticoids occurs through binding to the intracellular glucocorticoid receptor (GR) and mineralocorticoid receptor (MR) [47, 48], mediating the transcription of pro-inflammatory genes and regulating epidermal proliferation and differentiation $[47,49]$.

Early cell models studies showed that exposure to glucocorticoids resulted in down-regulation of GR DNA and mRNA [50, 51]. Subsequent studies have gone further to study variations in the two splicing variants of GR, the GRa and GRb isoform [52, 53]. In 2009, Hagg [52] observed that following TCS treatment, patients with poor clinical response had upregulated GRb expression while this was unchanged in patients with good clinical response. Authors postulated that the increased expression of GRb correlated with glucocorticoid insensitivity in atopic dermatitis. Further studies are required to confirm the association between expression of GR and its isoforms and steroid responsiveness.

\subsection{Dysregulation of Cortisol Production by Keratinocytes}

In 2016, Fukaya postulated that TSA/TSW was due to suppressed production of cortisol in keratinocytes after TCS use [54]. He stained skin biopsy specimens from 8 patients with atopic dermatitis and 1 healthy control with anti-cortisol antibody. In patients with rebound phenomenon after stopping TCS, the cortisol pattern in the epidermis had a patchy staining of anti-cortisol antibody, compared to a homogenous staining in healthy patients or those recovered from TSA/TSW. He hypothesised that TCS application causes a decrease in self-production of cortisol by keratinocytes. However, a second study by Fukaya in 2017 showed an increase in cortisol staining in the epidermis with TCS application, followed by a decrease after cessation in a single healthy volunteer after 2 weeks of clobetasol propionate application [53]. The evidence for this thus remains unclear.

\subsection{Rebound Vasodilation}

The clinical efficacy and potency of the TCS is correlated with the degree of vasoconstriction it induces [2, 55]. This is mediated through suppressed production of vasodilators like nitric oxide (NO), histamine, and mediators of vascular smooth muscle reactivity $[35,56]$.

A study of 12 patients with red scrotum syndrome reported predominant features of burning, pain and bright erythematous skin together with ectatic venules in 4 out of 7 patients on histology [24]. This led the authors to propose a vasodilatory and neurovascular mechanism for TSA/TSW.

Rapaport and Rapaport [12, 57] postulated that the erythema and burning seen in TSA/TSW is caused by rebound vasodilation mediated by NO. A group of 38 patients with TSA had their serum NO compared against controls who had either recovered from TSA/TSW or had mild eczema. Patients with TSA/TSW had a statistically higher mean NO level compared to the control group and most showed a temporal decrease in serum NO levels after TCS cessation (without details on clinical improvement). However, the study was unable to demonstrate a temporal relation between elevated NO level and the presence of the flare and it is unclear if the level of elevation of serum NO in the TSA/ TSW group could account for the clinical signs. 
Previous studies have also shown that inflammatory skin diseases such as atopic dermatitis are associated with higher levels of serum NO [58, 59]. Thus, it cannot be concluded if the elevated NO is related to TSA/TSW or the underlying inflammatory skin condition. Finally, NO seems to exhibit both anti- or pro-inflammatory effects [60-62] depending on its concentration and microenvironment, with studies showing beneficial anti-inflammatory effects of topical NOreleasing compounds $[62,63]$. Further investigation into the relationship between NO levels, disease course and treatment will be helpful.

\subsection{Rebound Cytokine Cascade Secondary to TCS Induced Barrier Impairment}

TCS use has been shown to result in barrier dysfunction [37, 44, 64]. In a hairless mouse model study, Lin et al [37] found that cessation of $0.064 \%$ betamethasone dipropionate ointment after a 6-week use led to an increase in transepidermal water loss (TEWL), higher expression of Ki-67 (a cell proliferative marker) and upregulation of IL1- $\alpha$, TNF- $\alpha$ and $\mathrm{NF}-\kappa \mathrm{B}$. These cytokines gradually normalised after 1 week. Authors proposed that the barrier disruption from TCS use induces a cytokine cascade once the anti-inflammatory effects of TCS are withdrawn, manifesting in a withdrawal dermatitis. Interestingly, concurrent application of petrolatum during TCS use had attenuated the barrier impairment and cytokine production suggesting the importance of concurrent moisturisers.

\section{Investigations}

A patch test is useful in excluding an allergic contact dermatitis to TCS [12], although challenges include the lack of normal skin for patch testing, false negative results due to delayed reactions and false positive due to vasodilation $[12,65]$. Skin histology of patients with TSA/TSW is nonspecific, with epidermal atrophy [31], spongiosis [12, 16], and parakeratosis described [16].

\section{Treatment}

Treatment recommended by various authors primarily involves tapering [14] or complete cessation of TCS [12, 15]. The rationale proposed for an immediate cessation without a taper is that the vasoconstrictive properties of TCS contributing to TSA/TSW would still remain despite a lower potency [12].

General measures recommended during the withdrawal phase include lifestyle modifications such as dietary changes and stress control [12], psychological support [12, 15, 18], cold water and ice $[12,66]$, systemic antibiotics and astringents to prevent and treat concomitant bacterial infection $[12,15]$, analgesics [12] sedatives [12] antihistamines [66], anxiolytics [12], and oatmeal-containing bath products [12]. Other treatments tried include topical calcineurin inhibitors [67], crisaborole [67], phototherapy [67], cyclosporin [12, 67], and dupilumab [67]. Acneiform eruptions like steroid rosacea and perioral dermatitis can be treated with oral antibiotics such as doxycycline [66]. Response to therapy was inconsistent and studies were low quality, being limited to case reports or small series and thus cannot be used to generate recommendations for treatment.

\section{Prognosis}

Complete cure and resolution were reported to have occurred between weeks to years [10, 12, 15, 23, 26]. However, there is considerable variability in persistence of outcomes. Cessation of TCS in 24 atopic dermatitis patients with concerns of TSW led to improvements in symptom severity and DLQI scores over 2 years [26]. A study by Juhász et al from California, which reviewed blogs of children with reported TSA/ TSW reported that 7 of 13 subjects continued to have "active TSA/TSW symptoms such as shedding, oozing, erythema, pain and itching" even 20 months after cessation of TCS [23]. A survey of 3840 participants with self-reported TSA/ TSW found that $26 \%$ of those who had stopped TCS for greater than 5 years reported persistence of symptoms [68].

\section{Discussion}

Is there a basis for steroid phobia? Current evidence for TSA/TSW is insufficient and at points contradictory. Furthermore, majority of the studies are of low quality and at high risk of bias. Certain authors describe distinct clinical presentations of TSA/TSW; however, there is no consensus on a diagnostic criterion or the patterns of associated TCS use that result in TSA/TSW. It also remains difficult to concretely establish a difference between TSA/TSW and a flare of the pre-existing inflammatory skin diseases. Additionally, experimental studies of short TCS application in healthy volunteers may not be generalisable to dermatological patients with chronic TCS use. Despite these limitations, we believe it is still rational to entertain the possibility of TSA/TSW, given the non-conclusive nature of existing research and the mechanistic potential of tolerance, withdrawal and rebound reported with other medications such as intranasal vasoconstrictors [69], benzodiazepines [70], histamine-2 receptor blockers [71], antidepressants [72] and oral steroids [73].

Although TSA/TSW is a controversial entity in the medical community, there are online communities of patients who 
report experiencing TSA/TSW. Medical professionals who fail to acknowledge the concerns of this group risk being viewed as dismissive and many patients will instead seek alternative treatments including those from online support groups (ongoing study). Various medical and dermatological groups now have public facing pages acknowledging the entity of TSA/ TSW. For example, the British Association of Dermatologists and National Eczema Society recently published a joint position statement on TSA/TSW in January 2021, tactfully addressing TSA/TSW without comment on its validity [74].

Further research into TCS use in groups without an underlying primary inflammatory skin disorder, varying potencies and durations of TCS use, and longitudinal studies with a control arm would be important. A multi-omic analytic approach (e.g., metabolomics, microbiomics, proteomics and lipidomics) may help in further delineating the difference between TSA/TSW and the underlying primary inflammatory skin disorder. Concurrently, the development and evaluation of different TCS formulations and application regimes [75] may result in fewer side effects, systemic absorption and skin atrophogenicity [76, 77]. Non-steroidal topical therapies $[78,79]$ will help to provide alternate options for patients who wish to avoid or reduce the side effects of TCS. Finally, engagement of patient support groups by the medical community and an open and objective discourse about TSW/TSW is needed to foster mutual respect and trust.

\section{Conclusion}

TCS are useful for many patients who suffer from inflammatory skin diseases. The challenge for dermatologists is in deciding treatment potency and duration to obtain the greatest benefits with the least number of side effects. In scientifically reviewing the clinical presentations and postulated mechanisms surrounding this controversial topic of TSA/TSW, medical practitioners and patients may better approach the use or non-use of TCS with greater objectivity and awareness.

\section{Declarations}

Author Contributions EC, ST, NSC conceived the review idea. EC and NSC performed the search and EC and ST filtered the articles for inclusion. All authors reviewed the included manuscripts and contributed equally to the drafting and review of the manuscript.

Funding This review was funded by the Chan Heng Leong Research Award, National University Hospital. The funding organization had no role in the design, conduct, interpretation, review, or approval of the manuscript.

Conflict of interest The authors have no personal or financial conflicts of interests to disclose.
Ethical approval Not applicable.

Informed consent Not applicable.

Consent for publication Not applicable.

Availability of data and material Data and study material are available on reasonable request.

Code availability Not applicable.

Open Access This article is licensed under a Creative Commons Attribution-NonCommercial 4.0 International License, which permits any non-commercial use, sharing, adaptation, distribution and reproduction in any medium or format, as long as you give appropriate credit to the original author(s) and the source, provide a link to the Creative Commons licence, and indicate if changes were made. The images or other third party material in this article are included in the article's Creative Commons licence, unless indicated otherwise in a credit line to the material. If material is not included in the article's Creative Commons licence and your intended use is not permitted by statutory regulation or exceeds the permitted use, you will need to obtain permission directly from the copyright holder. To view a copy of this licence, visit http://creativecommons.org/licenses/by-nc/4.0/.

\section{References}

1. Thomas M, Wong CC, Anderson P, Grills N. Magnitude, characteristics and consequences of topical steroid misuse in rural North India: an observational study among dermatology outpatients. BMJ Open. 2020;10(5):e032829.

2. Hengge UR, Ruzicka T, Schwartz RA, Cork MJ. Adverse effects of topical glucocorticosteroids. J Am Acad Dermatol. 2006;54(1):1-15 (quiz 16-8).

3. Li AW, Yin ES, Antaya RJ. Topical corticosteroid phobia in atopic dermatitis: a systematic review. JAMA Dermatol. 2017;153(10):1036-42.

4. Stalder J-F, Aubert H, Anthoine E, Futamura M, Marcoux D, Morren M-A, et al. Topical corticosteroid phobia in atopic dermatitis: International feasibility study of the TOPICOP score. Allergy. 2017;72(11):1713-9.

5. Choi E, Tan KW, Tang F, Tan C, Chandran NS. Efficacy of targeted education in reducing topical steroid phobia: a randomized clinical trial. J Am Acad Dermatol. 2020;83(6):1681-7.

6. Choi E, Chandran NS, Tan C. Corticosteroid phobia: a questionnaire study using TOPICOP score. Singapore Med J. 2020;61(3):149-53.

7. Saito-Abe M, Futamura M, Yamamoto-Hanada K, Yang L, Suzuki $\mathrm{K}$, Ohya Y. Topical corticosteroid phobia among caretakers of children with atopic dermatitis: a cross-sectional study using TOPICOP in Japan. Pediatr Dermatol. 2019;36(3):311-6.

8. Hon KL, Leong KF, Leung TN, Leung AK. Dismissing the fallacies of childhood eczema management: case scenarios and an overview of best practices. Drugs Context. 2018;7:212547.

9. Hon K-LE, Leung TF, Yau HC, Chan T. Paradoxical use of oral and topical steroids in steroid-phobic patients resorting to traditional Chinese medicines. World J Pediatr. 2012;8(3):263-7.

10. Hajar T, Leshem YA, Hanifin JM, Nedorost ST, Lio PA, Paller AS, et al. A systematic review of topical corticosteroid withdrawal ('steroid addiction') in patients with atopic dermatitis and other dermatoses. J Am Acad Dermatol. 2015;72(3):541-549.e2. 
11. Hwang J, Lio PA. Topical corticosteroid withdrawal ('steroid addiction'): an update of a systematic review. J Dermatolog Treat. 2021;4:1-6.

12. Rapaport MJ, Rapaport V. The red skin syndromes: corticosteroid addiction and withdrawal. Expert Rev Dermatol. 2006;1(4):547-61.

13. Ghosh A, Sengupta S, Coondoo A, Jana AK. Topical corticosteroid addiction and phobia. Indian J Dermatol. 2014;59(5):465-8.

14. Kligman AM, Frosch PJ. Steroid addiction. Int J Dermatol. 1979;18(1):23-31.

15. Fukaya M, Sato K, Sato M, Kimata H, Fujisawa S, Dozono H, et al. Topical steroid addiction in atopic dermatitis. Drug Healthc Patient Saf. 2014;14(6):131-8.

16. Sheary B. Steroid withdrawal effects following long-term topical corticosteroid use. Dermatitis. 2018;29(4):213-8.

17. Rapaport MJ, Rapaport V. Eyelid dermatitis to red face syndrome to cure: clinical experience in 100 cases. J Am Acad Dermatol. 1999;41(3 Pt 1):435-42.

18. Lahiri K, Coondoo A. Topical steroid damaged/dependent face (TSDF): an entity of cutaneous pharmacodependence. Indian J Dermatol. 2016;61(3):265-72.

19. Pal D, Biswas P, Das S, De A, Sharma N, Ansari A. Topical Steroid Damaged/Dependent Face (TSDF): a Study from a Tertiary Care Hospital in Eastern India. Indian J Dermatol. 2018;63(5):375-9.

20. Rapaport MJ, Rapaport V. Prolonged erythema after facial laser resurfacing or phenol peel secondary to corticosteroid addiction. Dermatol Surg. 1999;25(10):781-4 (discussion 785).

21. Jain S, Mohapatra L, Mohanty P, Jena S, Behera B. Study of clinical profile of patients presenting with topical steroid-induced facial dermatosis to a Tertiary Care Hospital. Indian Dermatol Online J. 2020;11(2):208-11.

22. Bhat YJ, Manzoor S, Qayoom S. Steroid-induced rosacea: a clinical study of 200 patients. Indian J Dermatol. 2011;56(1):30-2.

23. Juhász MLW, Curley RA, Rasmussen A, Malakouti M, Silverberg $\mathrm{N}$, Jacob SE. Systematic review of the topical steroid addiction and topical steroid withdrawal phenomenon in children diagnosed with atopic dermatitis and treated with topical corticosteroids. J Dermatol Nurses' Assoc. 2017;9(5):233-40.

24. Narang T, Kumaran MS, Dogra S, Saikia UN, Kumar B. Red scrotum syndrome: idiopathic neurovascular phenomenon or steroid addiction? Sex Health. 2013;10(5):452-5.

25. Feldmann RJ, Maibach HI. Regional variation in percutaneous penetration of $14 \mathrm{C}$ cortisol in man. J Invest Dermatol. 1967;48(2):181-3.

26. Sheary B, Harris MF. Cessation of long-term topical steroids in adult atopic dermatitis: a prospective cohort study. Dermatitis. 2020;31(5):316-20.

27. Nnoruka E, Okoye O. Topical steroid abuse: its use as a depigmenting agent. J Natl Med Assoc. 2006;98(6):934-9.

28. Xiao X, Xie H, Jian D, Deng Y, Chen X, Li J. Rebounding triad (severe itching, dryness and burning) after facial corticosteroid discontinuation defines a specific class of corticosteroid-dependent dermatitis. J Dermatol. 2015;42(7):697-702.

29. Sneddon I. Adverse effect of topical fluorinated corticosteroids in rosacea. Br Med J. 1969;1(5645):671-3.

30. Rathi SK, Kumrah L. Topical corticosteroid-induced rosacealike dermatitis: a clinical study of 110 cases. Indian J Dermatol Venereol Leprol. 2011;77(1):42-6.

31. Zheng P, Lavker RM, Lehmann P, Kligman AM. Morphologic investigations on the rebound phenomenon after corticosteroid-induced atrophy in human skin. J Investig Dermatol. 1984;82(4):345-52.

32. Uva L, Miguel D, Pinheiro C, Antunes J, Cruz D, Ferreira J, et al. Mechanisms of action of topical corticosteroids in psoriasis. Int $\mathbf{J}$ Endocrinol. 2012;2012:561018.
33. Croxtall JD, van Hal PTW, Choudhury Q, Gilroy DW, Flower RJ. Different glucocorticoids vary in their genomic and nongenomic mechanism of action in A549 cells. Br J Pharmacol. 2002;135(2):511-9.

34. Kirby JD, Munro DD. Steroid-induced atrophy in an animal and human model. Br J Dermatol. 1976;94(suppl 12):111-9.

35. Marks R, Sawyer M. Glucocorticoid-induced vasoconstriction in human skin: an inhibitory role on phospholipase A2 activity. Arch Dermatol. 1986;122(8):881-3.

36. Barnes L, Kaya G, Rollason V. Topical corticosteroid-induced skin atrophy: a comprehensive review. Drug Saf. 2015;38(5):493-509.

37. Lin T-K, Wei K-J, Wu C-H, Lai F-J, Lan C-CE, Chang C-H, et al. Barrier abnormalities and keratinocyte-derived cytokine cascade after cessation of long-term topical glucocorticosteroid on hairless mouse skin. Dermatol Sin. 2015;33(2):103-11.

38. Lubach D, Rath J, Kietzmann M. Skin atrophy induced by initial continuous topical application of clobetasol followed by intermittent application. Dermatology. 1995;190(1):51-5.

39. Andres P, Poncet M, Farzaneh S, Soto P. Short-term safety assessment of clobetasol propionate $0.05 \%$ shampoo: hypothalamicpituitary-adrenal axis suppression, atrophogenicity, and ocular safety in subjects with scalp psoriasis. J Drugs Dermatol. 2006;5(4):328-32.

40. Serup J, Holm P. Domoprednate (Stermonid), a topical D-homocorticosteroid, skin atrophy and telangiectasia. A double-blind, randomized comparison with hydrocortisone butyrate, betamethasone valerate, clobetasole propionate and placebo. Dermatologica. 1985;170(4):189-94.

41. Cossmann M, Welzel J. Evaluation of the atrophogenic potential of different glucocorticoids using optical coherence tomography, $20-\mathrm{MHz}$ ultrasound and profilometry; a double-blind, placebocontrolled trial. Br J Dermatol. 2006;155(4):700-6.

42. Kolbe L, Kligman AM, Schreiner V, Stoudemayer T. Corticosteroid-induced atrophy and barrier impairment measured by non-invasive methods in human skin. Skin Res Technol. 2001;7(2):73-7.

43. du Vivier A, Phillips H, Hehir M. Applications of glucocorticosteroids: the effects of twice-daily vs once-every-other-day applications on mouse epidermal cell DNA synthesis. Arch Dermatol. 1982;118(5):305-8.

44. du Vivier A. Tachyphylaxis to topically applied steroids. Arch Dermatol. 1976;112(9):1245-8.

45. du Vivier A, Stoughton RB. Tachyphylaxis to the action of topically applied corticosteroids. Arch Dermatol. 1975;111(5):581-3.

46. Singh S, Gupta A, Pandey SS, Singh G. Tachyphylaxis to histamine-induced wheal suppression by topical $0.05 \%$ clobetasol propionate in normal versus croton oil-induced dermatitic skin. Dermatology. 1996;193(2):121-3.

47. Bigas J, Sevilla LM, Carceller E, Boix J, Pérez P. Epidermal glucocorticoid and mineralocorticoid receptors act cooperatively to regulate epidermal development and counteract skin inflammation. Cell Death Dis. 2018;9(6):1-14.

48. Vandevyver S, Dejager L, Libert C. Comprehensive overview of the structure and regulation of the glucocorticoid receptor. Endocr Rev. 2014;35(4):671-93.

49. Sevilla L, Latorre V, Sanchis A, Perez P. Epidermal inactivation of the glucocorticoid receptor triggers skin barrier defects and cutaneous inflammation. J Invest Dermatol. 2012;6:133.

50. Burnstein KL, Jewell CM, Sar M, Cidlowski JA. Intragenic sequences of the human glucocorticoid receptor complementary DNA mediate hormone-inducible receptor messenger RNA down-regulation through multiple mechanisms. Mol Endocrinol. 1994;8(12):1764-73.

51. Pujols L, Mullol J, Pérez M, Roca-Ferrer J, Juan M, Xaubet A, et al. Expression of the human glucocorticoid receptor alpha and beta isoforms in human respiratory epithelial cells and 
their regulation by dexamethasone. Am J Respir Cell Mol Biol. 2001;24(1):49-57.

52. Hägg PM, Hurskainen T, Palatsi R, Ilves M, Oikarinen A. Increased expression of glucocorticoid receptor beta in lymphocytes of patients with severe atopic dermatitis unresponsive to topical corticosteroid. Br J Dermatol. 2010;162(2):318-24.

53. Fukaya M. Cortisol homeostasis in the epidermis is influenced by topical corticosteroids in patients with atopic dermatitis. Indian J Dermatol. 2017;62(4):440

54. Fukaya M. Histological and immunohistological findings using anti-cortisol antibody in atopic dermatitis with topical steroid addiction. Dermatol Ther (Heidelb). 2016;6(1):39-46.

55. Stoughton RB. Bioassay system for formulations of topically applied glucocorticosteroids. Arch Dermatol. 1972;106(6):825-7.

56. Yang S, Zhang L. Glucocorticoids and vascular reactivity. Curr Vasc Pharmacol. 2004;2(1):1-12.

57. Rapaport MJ, Rapaport VH. Serum nitric oxide levels in 'red' patients: separating corticosteroid-addicted patients from those with chronic eczema. Arch Dermatol. 2004;140(8):1013-4.

58. Gokhale NR, Belgaumkar VA, Pandit DP, Deshpande S, Damle DK. A study of serum nitric oxide levels in psoriasis. Indian J Dermatol Venereol Leprol. 2005;71(3):175-8.

59. Akdeniz N, Aktaş A, Erdem T, Akyüz M, Özdemir Ş. Nitric oxide levels in atopic dermatitis. Pain Clin. 2004;16(4):401-5.

60. Muijsers RB, Folkerts G, Henricks PA, Sadeghi-Hashjin G, Nijkamp FP. Peroxynitrite: a two-faced metabolite of nitric oxide. Life Sci. 1997;60(21):1833-45.

61. Moilanen E, Vapaatalo H. Nitric oxide in inflammation and immune response. Ann Med. 1995;27(3):359-67.

62. Guttman-Yassky E, Gallo RL, Pavel AB, Nakatsuji T, Li R, Zhang $\mathrm{N}$, et al. A nitric oxide-releasing topical medication as a potential treatment option for atopic dermatitis through antimicrobial and anti-inflammatory activity. J Invest Dermatol. 2020;140(12):25312535.e2.

63. Hyun E, Bolla M, Steinhoff M, Wallace JL, del Soldato P, Vergnolle N. Anti-inflammatory effects of nitric oxide-releasing hydrocortisone NCX 1022, in a murine model of contact dermatitis. Br J Pharmacol. 2004;143(5):618-25.

64. Kao JS, Fluhr JW, Man M-Q, Fowler AJ, Hachem J-P, Crumrine $\mathrm{D}$, et al. Short-term glucocorticoid treatment compromises both permeability barrier homeostasis and stratum corneum integrity: inhibition of epidermal lipid synthesis accounts for functional abnormalities. J Invest Dermatol. 2003;120(3):456-64.

65. Matura M, Goossens A. Contact allergy to corticosteroids. Allergy. 2000;55(8):698-704.

66. Sheary B. Topical steroid withdrawal: a case series of 10 children. Acta Derm Venereol. 2019;99(6):551-6.

67. Arnold KA, Treister AD, Lio PA. Dupilumab in the management of topical corticosteroid withdrawal in atopic dermatitis: a retrospective case series. JAAD Case Rep. 2018;4(9):860-2.

68. Berger T, Francis-Lyon P, Parker J, Friedman P, Sengar P, Owens J. Analysis of patient-reported symptoms with respect to TCS usage: a self-identified cohort of patients with RSS/TSA/TSW. J Am Acad Dermatol. 2017;76(6):AB44.

69. Graf P. Long-term use of oxy- and xylometazoline nasal sprays induces rebound swelling, tolerance, and nasal hyperreactivity. Rhinology. 1996;34(1):9-13.

70. Higgitt A, Fonagy $\mathrm{P}$, Lader $\mathrm{M}$. The natural history of tolerance to the benzodiazepines. Psychol Med Monogr Suppl. 1988;13:1-55.

71. McRorie JW, Kirby JA, Miner PB. Histamine2-receptor antagonists: rapid development of tachyphylaxis with repeat dosing. World J Gastrointest Pharmacol Ther. 2014;5(2):57-62.

72. Kinrys G, Gold AK, Pisano VD, Freeman MP, Papakostas GI, Mischoulon D, et al. Tachyphylaxis in major depressive disorder: a review of the current state of research. J Affect Disord. 2019;15(245):488-97.
73. Forte WCN, Sumita JM, Rodrigues AG, Liuson D, Tanaka E. Rebound phenomenon to systemic corticosteroid in atopic dermatitis. Allergol Immunopathol (Madr). 2005;33(6):307-11.

74. National Eczema Society, British Association of Dermatologists. National Eczema Society and British Association of Dermatologists joint position statement on Topical Steroid Withdrawal [Internet]. 2021. https://eczema.org/wp-content/uploads/Topical-Stero id-Withdrawal-position-statement.pdf. Accessed 31 Jan 2021.

75. Kawakami T, Soma Y, Morita E, Koro O, Yamamoto S, Nakamura $\mathrm{K}$, et al. Safe and effective treatment of refractory facial lesions in atopic dermatitis using topical tacrolimus following corticosteroid discontinuation. Dermatology. 2001;203(1):32-7.

76. Spada F, Barnes TM, Greive KA. Comparative safety and efficacy of topical mometasone furoate with other topical corticosteroids. Australas J Dermatol. 2018;59(3):e168-74.

77. Norsgaard H, Kurdykowski S, Descargues P, Gonzalez T, Marstrand T, Dünstl G, et al. Calcipotriol counteracts betamethasoneinduced decrease in extracellular matrix components related to skin atrophy. Arch Dermatol Res. 2014;306(8):719-29.

78. Frankel A, Sohn A, Patel RV, Lebwohl M. Bilateral comparison study of pimecrolimus cream $1 \%$ and a ceramide-hyaluronic acid emollient foam in the treatment of patients with atopic dermatitis. J Drugs Dermatol. 2011;10(6):666-72.

79. Fukaya M, Kimata H. Topical clofibrate improves symptoms in patients with atopic dermatitis and reduces serum TARC levels: a randomized, double-blind, placebo-controlled pilot study. J Drugs Dermatol. 2014;13(3):259-63.

80. Sheu HM, Lee JY, Kuo KW, Tsai JC. Permeability barrier abnormality of hairless mouse epidermis after topical corticosteroid: characterization of stratum corneum lipids by ruthenium tetroxide staining and high-performance thin-layer chromatography. J Dermatol. 1998;25(5):281-9.

81. Hettmannsperger U, Tenorio S, Orfanos CE, Detmar M. Corticosteroids induce proliferation but do not influence TNF- or IL-1 beta-induced ICAM-1 expression of human dermal microvascular endothelial cells in vitro. Arch Dermatol Res. 1993;285(6):347-51.

82. Kligman AM. Letter: topical steroid addicts. JAMA. 1976;235(15):1550.

83. Colomb D. Stellate spontaneous pseudoscars. Senile and presenile forms: especially those forms caused by prolonged corticoid therapy. Arch Dermatol. 1972;105(4):551-4.

84. Adam JE, Craig G. Striae and their relation to topical steroid therapy. Can Med Assoc J. 1965;92(6):289-91.

85. Shuster S. The cause of striae distensae. Acta Derm Venereol Suppl (Stockh). 1979;59(85):161-9.

86. Nigam PK. Striae cutis distensae. Int J Dermatol. 1989;28(7):426-8.

87. Friedman SJ, Butler DF, Pittelkow MR. Perilesional linear atrophy and hypopigmentation after intralesional corticosteroid therapy. Report of two cases and review of the literature. J Am Acad Dermatol. 1988;19(3):537-41.

88. Truhan AP, Ahmed AR. Corticosteroids: a review with emphasis on complications of prolonged systemic therapy. Ann Allergy. 1989;62(5):375-91.

89. Takeda K, Arase S, Takahashi S. Side effects of topical corticosteroids and their prevention. Drugs. 1988;36(Suppl 5):15-23.

90. Dolenc-Voljc M, Pohar M, Lunder T. Density of Demodex folliculorum in perioral dermatitis. Acta Derm Venereol. 2005;85(3):211-5.

91. Kaidbey KH, Kligman AM. The pathogenesis of topical steroid acne. J Invest Dermatol. 1974;62(1):31-6.

92. Aucott JN. Glucocorticoids and infection. Endocrinol Metab Clin N Am. 1994;23(3):655-70.

93. Choi E, Tan CL, Aw D. Malassezia: a case of coexisting pityriasis versicolor and Malassezia folliculitis. Singapore Med J. 2020;61(4):221. 